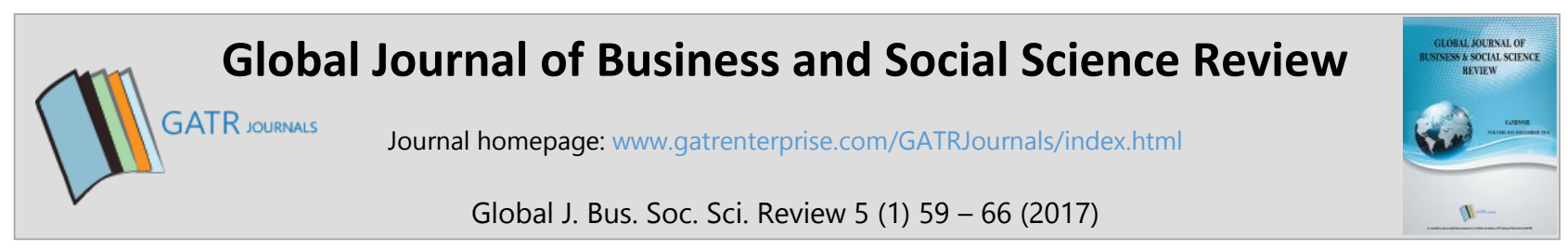

\title{
Government Initiatives for development of Rural Economy in India: Benefits \& Challenges (2014-2016)
}

\author{
Tina Shivnani * \\ Manipal University Jaipur, VPO Dehmi Kalan,Tehsil Sanganer Off Jaipur-Ajmer Expressway Jaipur, 302007 India
}

\begin{abstract}
Objective -In this paper, the researcher attempt to find out how many schemes for development have been launched by the Indian Government and the various benefits and challenges of adopting these schemes in rural India. The research paper focuses on whether the schemes have helped to connect rural people and whether they have been successful in fulfilling the basic needs of rural people.

Methodology/Technique - The study reviews literature in the related area.

Findings - The current government has already come up with so many social and financial alleviation schemes for the poor; however, the fate of those unfortunates still remains a concern.

Novelty - The study attempts to provide insight to reforms of poverty in India.

Type of Paper: Review.
\end{abstract}

Keywords: Rural people, Indian Government Schemes, Rural Development, Challenges, Benefits from Schemes.

JEL Classification: P25, P27.

\section{Introduction}

India is considered to be the 7th largest economy in the world by nominal Gross Domestic Product (GDP) and is considered to be the $3^{\text {rd }}$ largest by Purchasing Power Parity (PPP). It is an emerging economy with around $7 \%$ average growth rate recorded in last few years. Very recently, India's economy became the world's fastest growing economy, replacing China from the last quarter of 2014. The growth prospects of the Indian economy are seen as positive due to its young population, healthy savings and investment rates. The agricultural sector of India is the one of the largest contributors to India's economy. Over the years, this contribution has been declining its share of the GDP by around $15 \%$. Still, India ranks $2^{\text {nd }}$ worldwide in agricultural output. It is said that with the right adoption of technology and policies, India could contribute to feeding not just itself, but the world. A large part of the Indian population lives in rural areas and most of them are not covered under any kind of social security scheme. A large section of this population has not even gained the benefits of the banking system and most are still unaware of various governmental schemes that are lunched from time to time. If any such scheme is not able to reach the masses with adequate information and

\footnotetext{
* Paper Info: Revised: September, 2016

Accepted: January, 2017

* Corresponding author:

E-mail: teenashivnani13@gmail.com

Affiliation: Manipal University Jaipur, India
} 
advertisement, the entire purpose of the scheme may fail. Several welfare initiatives and schemes introduced in the last 2 years speak out loud of the success India has experienced like never before. Prime Minister Modi has continuously emphasized the need for development of infrastructure, employment, skills and women's safety for the betterment of the country. With the intention of developing rural India, Prime Minister Narendra Modi has launched various schemes for rural development (2014- 2016) which was pushed to a great extent by "Acche Din Aa Gaye".

\section{Review of Literature}

According to Gangopadhyay et al. (2008), although various initiative have been taken by the Indian government to alleviate poverty in rural areas, there is still a lot of effort required to bring wealth to the rural people. Presently technology diffusion is slow in rural areas. In India, technology plays a vital role for rural development and will do so for the foreseeable and near future. Nair (2014) observed that people living in the rural areas struggle to earn wages and are forced to travel to urban areas. Such movements severely affect the quality of life, lack of education and social burdens leading to destruction of moral values in the rural areas. Nair also discusses the various challenges faced by rural people and suggests ways to overcome these challenges and to create opportunities of gainful self-employment for rural families, especially those disadvantaged sections, ensuring sustainable livelihood, enriched environment, improved quality of life and good human values. She states that the appropriate extension of technologies and upgrading of skills will increase the quality of life of rural people. Bhatia and Kiran (2016) have stated that around 80\% of India's population live in rural areas. Technology plays a vital role in improving rural areas in India. Information and Communication Technology (ICT) acts as a provider of major openings to rural livelihoods and contributes towards poverty reduction. Petare (2013) in his research paper focused on the relationship between ICT and rural development; the government of India has taken initiatives for rural development with the help of ICT in India. Petare also discusses the issues and problems in rural development after the implementation of the ICT.

The various government initiatives and schemes lunched by Prime Minister Modi are as follows:

\section{Pradhan Mantri Jan DhanYojana (PMJDY): Launched: 28 August 2014}

Pradhan Mantri Jan Dhan Yojana (PMJDY) is a national mission aimed at achieving comprehensive financial inclusion for all households in India. Under the PMJDY, any individual above the age of 10 years who does not have a bank account can open a bank account without depositing any money. The scheme was to ensure access to financial services such as savings and deposit accounts, remittance, credit, debit cards, insurance and pension in an affordable manner. The scheme was mostly targeted to those people living below the poverty line but is beneficial to everyone who does not have a bank account.

This financial inclusion campaign was launched by the Prime Minister of India on 28 August 2014. He had announced this scheme in his first Independence Day speech on 15 August 2014. Jan Dhan Yojana has been a great success; around 21 Crore accounts have been opened in approximately one and a half years under the scheme. Out of the total, 12.87 Crore accounts were opened in rural areas and 8.13 Crore accounts have been opened in urban areas. According to Khuntia, (2014) Guinness World Records Recognizes Pradhan Mantri Jan-Dhan Yojana as the scheme resulting in the maximum number of bank accounts being opened in one week.

\section{Benefits:}

- Interest on deposit.

- In built accident insurance cover of Rs. 1 lakh with RuPay Debit Card given to the account holder.

- No minimum balance required.

- Easy transfer of money across India.

- Beneficiaries of government schemes will get direct benefit transfer in that account. 
- Access to pension, insurance product.

- Availability of overdraft facility after satisfactory operation of A/C for 6 months up to Rs. 5,000 but in only one account per household preferably lady of the household.

- Account holders receive cheque book, literature on financial literacy and pass book in a kit.

Challenges:

- Many cases have been detected where an individual has opened more than one account in various banks.

- Insurance companies have to fix a nominal premium to cover the risk of the account holders.

- KYC norms are not insisted under this programme therefore, duplication is unavoidable.

- RBI has to accord approval to banks so as to enable them to establish more branches, keeping in view the number of villages and the population.

\section{Swachh Bharat Mission (Gramin): Launched: 2 October 2014}

To accelerate efforts to achieve universal sanitation coverage and to put focus on sanitation, the Prime Minister of India launched the Swachh Bharat Mission on 2nd October 2014 with two sub-missions; the Swach Bharat Mission (Gramin) and the Swachh Bharat Mission (Urban). It aims to achieve Swachh Bharat by 2019 , as a fitting tribute to the 150th Birth Anniversary of Mahatma Gandhi.

The aim of this mission it to improve the general quality of life in rural areas by promoting cleanliness, hygiene and eliminating open defecation. It motivates communities and Panchayati Raj Institutions to adopt sustainable sanitation practices and facilities through raising awareness and health education. This mission encourages cost effective and appropriate technologies for ecologically safe and sustainable sanitation.

3. Make in India: Lunched in $25^{\text {th }}$ Sep. 2014

The Make in India initiative launched by Prime Minister Narendra Modi on 25th September 2014 aims to promote India a global manufacturing hub. Under this initiative, companies across the globe are invited to make an investment and set up factories or expand their facilities in India, using India's highly talented and skilled manpower to create world class, zero defect products. The Mission aims to stimulate manufacturing in India for sale in the global market. It also aims to creating millions of jobs in the country. Under the 'Make in India' initiative, the government has taken several steps to improve India's business environment in order to attract foreign investments. The major initiative is to encourage companies to increase their manufacture in India. This not only includes attracting overseas companies to set up shop in India, but also encouraging domestic companies to increase production within the country.

Benefits:

- Make in India is an initiative of the government of India aimed at encouraging multinational, as well as domestic, companies to manufacture their products in India.

- The major focus is on job creation and skill enhancement in 25 sectors of the economy.

- It aims at increasing the GDP and tax revenues in the country, by producing products that meet high quality standards, and minimizing the impact on the environment.

4. BetiBachao, BetiPadhaoYojana: Launched: 22 January 2015 
The Census (2011) data showed a significant declining trend in the Child Sex Ratio (CSR) between 0-6 years with an all-time low of 918 in 2011. The issue of decline in the CSR is a major indicator of women disempowerment.

This sharp decline is a call for coordination and convergent efforts for survival, protection and education of the young girls. For this purpose, the government has announced the BetiPadhao (BBBP) Scheme in order to address the issue of decline in CSR through a mass campaign across the country, focusing on 100 gender critical districts with low CSR. While launching the programme, the Prime Minster stated that Indian people have common belief for that girls are the property of someone else other than their parents. Parents think that only boys are their property, as they have to look after them in the old age, however girls have to go another place to care for their in-laws. Such thinking in the 21st century needs to be eradicated and girls need to be given equal rights from birth.

This scheme aims to raise awareness about the importance of a girl's role in society. People should celebrate the birth of girls and educate them in the same way as boys. The scheme also aims to prevent gender biase, eliminate sex selective procedures, ensure the survival and protection of the girls and ensure their education.

\section{Pradhan Mantri Sukanya Samriddhi Yojana (PMSSY): Launched: 22 January 2015}

The objective behind this initiative is to address the gender imbalance and create a positive environment in for girls in India. It is the part of "BetiBachao-BetiPadhao". Sukanya Samriddhi Yojana is an ambitious small deposit savings scheme for a girl children. Under the scheme, a saving account can be opened in the name of girl child and deposits can be made for 14 years. After the girl child reaches 18 years of age, she can withdraw $50 \%$ of the amount for marriage or higher study purposes.

After the girl reaches 21 years of age, the maturity amount can be withdrawn including the interest at rates decided by Government every year. Where the family has more than one girl child, parents can open 2 separate accounts in different names but only for a maximum of 2 of the girl children.

The investments and returns are exempt from section 80C of Indian income tax act. The maximum investment of Rs. 1.5 Lakh per year can be made while the minimum deposit is Rs. 1000/- per year.

Benefits:

- Highest interest rate of $9.2 \%$ and exempted from Tax u/s $80 \mathrm{C}$.

- The maturity of the account is 21 years from date of opening or marriage of girl child whichever is earlier.

- Initial deposit of Rs.1000 and thereafter any amount in multiple of Rs.100 can be deposited to maximum of 1.5lakhs.

- $50 \%$ of the accumulated amount in the Sukanya Samriddhi Account can be withdrawn for the girl's higher education and marriage after she attains 18 years of age.

- The operation of the account shall not be permitted beyond the date of the girl's marriage.

Challenges:

- No fixed rate of interest on the deposit amount.

- Premature withdrawal is not allowed.

- It blocks the money for 21 years or girl child marriage whichever is earlier.

6. Pradhan Mantri MUDRA Yojana (PMMY): Launched: 8 April 2015 
Pradhan Mantri MUDRA (Micro Units Development and Refinance Agency) Yojana was launched with the purpose of providing low cost funding to the non-corporate small business sector. Pradhan Mantri Mudra Yojana (PMMY) is available from all bank branches across the country. The objective of the scheme is to encourage entrepreneurs and small business units to expand their capabilities and to reduce their debt. The small businesses/startups or entrepreneurs can access loans from Rs. 50 thousand to 10 Lakh to start/grow their business under the three, Shishu, Kishore and Tarun, categories of the scheme. The MUDRA is hopeful that under the scheme at least $60 \%$ of the credit provided is allocated to the Shishu category and the balance be allocated to the Kishore and Tarun categories. The schemes offered by the MUDRA bank are:

- Shishu-for starters. Covers loans up to Rs. 50,000.

- Kishor-for mid stage finance seekers . Covers loans above Rs. 50,000 and up to Rs. 500,000.

- Tarun- for growth seekers. Covers loan above Rs. 500,000 and up to Rs. 1,000,000.

Challenges:

- There are a number of already existing financing agencies i.e. NABARD \& SIDBI.

- There is a struggle of interest due to the various roles and responsibilities of the Mudra Bank.

7. Pradhan Mantri Garib Kalyan Yojanaye (PMGKY): Launched: $19^{\text {th }}$ April 2015

PMGKY was lunched by the Government of India in 2015 for people with low income. The objective of this scheme is to reduce the poverty levels of low class families. For this purpose, the government of India will be conducting a number of workshops under this scheme in different states. Any candidate can apply for the scheme and attend the workshop. These workshops will focus on the improvement of the lower income class and will introduce numerous sectional schemes for poverty alleviation.

When the scheme was lunch by Prime Minister Modi in 2015, he stated that the workshop will also be educating MPs about the various schemes so that they can implement the scheme at a grass root level, to eliminate poverty from their electorate. The vision behind these workshops is to engage the local representatives and give them an idea of how they encourage people to cooperate with the government in implementing these schemes. The Garib Kalyan Yojana workshop will revisit the government's pro-poor welfare programs and create ways to implement them efficiently and maximize their output.

8. Atal Pension Yojana (APY): Launched: 9 May 2015

Atal Pension Yojana is one of the three Jan Suraksha schemes launched by Prime Minister Narendra Modi. APY is aimed at increasing the number of pension scheme beneficiaries across the country. The scheme is especially targeted to the private unorganized sector and is open to all Indian citizens between the age of 18 and 40.

Under the scheme, the beneficiary has to make contributions for at least 20 years before they can access pension payments, after attaining age of 60 . The scheme provides a monthly pension of Rs 1000 to Rs. 5000 per month based on the contribution amount. The National Government would also co-contribute $50 \%$ of the total contribution or Rs. 1000 per annum, whichever is lower, to each eligible subscriber, for a period of 5 years. Under this scheme, the monthly pension would be available to the subscriber, and following death, to their spouse. The scheme is available to citizens aged between 18 and 40.

Benefits:

- A person can choose pension amounts of Rs. 1,000/2,000/3,000/4,000 and 5,000.

- Subscribers can access an auto-debit facility where the monthly contribution will be automatically deducted from the person's bank account. 
- The premium paid is eligible for deduction under section $80 \mathrm{CCD}$, with the upper limit capped at Rs. 50,000 .

- As per the new government rules (Aug. 2015), subscribers can also contribute their premium on a quarterly or half-yearly basis.

- In case of death, the subscriber's monthly pension will be paid to the spouse. The nominee of the account will receive the corpus up to a maximum of Rs. 8.5 lakhs in cases where both the subscriber and the spouse die.

Challenges:

- The government will contribute almost nothing - 50 percent of the subscriber's contribution or Rs 1,000 a year, whichever is lower, for only five years. The National Pension System (NPS) will manage the money.

- Investors find it hard to invest regularly month after month for years at a time.

9. Pradhan Mantri Jeevan Jyoti Bima Yojana (PMJJBY): Launched: 9 May 2015

Pradhan Mantri Jeevan Jyoti Bima Yojana is a life insurance scheme in India aimed at increasing the penetration of life insurance cover in India. The scheme is open and available to all Indian citizens between the age of 18 and 50. Under the scheme, the policy holder can get a life insurance cover of Rs. 2 Lakh with an annual premium of just Rs. 330 excluding service tax. All Indian citizens between 18 and 50 years of age with a saving bank account are eligible for the scheme.

Benefits:

- Rs.2 lakhs is payable on member's death due to any reason. The premium amount is Rs.330/- per annum per member.

- The premium will be deducted from the account holder's savings bank account through an 'auto debit' facility in one installment, as per the option given, on or before 31 st May of each annual coverage period under the scheme.

10. Pradhan Mantri Awas Yojana (PMAY): Launched: 25 June 2015

Pradhan Mantri Awas Yojana is an ambitious scheme of the Narendra Modi Government. Under the PMAY, the government aims to provide about 5 Crore affordable homes to the people belonging to EWS (Economically Weaker Section) and LIG (Lower Income Group) categories by the year 2022. The target of this scheme is to build 2 crore homes in urban areas and 3 crore in rural areas across the country. Under the scheme, the government will provide financial assistance to poor home buyers, interest subsidies on home loans and direct subsidies on homes bought under the scheme. A Technology Sub-Mission under the Mission has been set up to facilitate adoption of modern, innovative and green technologies and building material for faster and better quality construction of houses. The Technology Sub-Mission also facilitates preparation and adoption of layout designs and building plans suitable for various geo-climatic zones. The Awas Yojana will be available for women, transgender families, SC and ST people as well as urban homeless families belonging to the EWS and LIG categories.

Benefits:

- The ground floor of any house is preferably allotted to older people. 
- The construction of houses would be carried out through technology that is eco-friendly.

- Under the scheme, the allotment of homes will be conducted on the name of the female head of the household or in the joint name of women and his husband. This scheme would therefore be termed as a pro-women scheme.

- The government will provide an interest subsidy of $6.5 \%$ on housing loans, available for 15 years.

\section{Pradhan Mantri Gram Sinchai Yojana (PMGSY): Launched: 01 July 2015}

This scheme is aimed at attracting investments in irrigation systems at field level, developing and expanding cultivable land in the country, enhancing ranch water use in order to minimize wastage of water, enhancing crop per drop by implementing water-saving technologies and precision irrigation. Agriculture Minister Radha Mohan Singh has said that according to the union government's statistics, only 44 percent of the 14 crore hectares of arable land in the country is irrigated. The rest depends on monsoons. Under the programme, 'Soil Health Cards' (SHC) would be distributed among farmers to demonstrate the status and production capability of the farm soil in order for them to better understand its suitability to various types of crops. The government has approved Rs.50,000 crore for the implementation of Pradhan Mantri Gram Sinchai Yojana for the next 5 years (i.e. up to 2020).

\section{Skill India: Launched: 15 th July 2015}

The need for emphasis on rural India is based on the fact that almost 3 quaters of the populace lives in villages. Given the expansion of rural India, the majority of the country's landmass is within the rural landscape. These areas not only produce the bread and butter of the nation but also are highly awash with rich natural resources. For promoting rural development, Prime Minsiter Narendra Modi has launched a new programme called "Skill India". It is intended to be a multi-skill programme. The main goal is to create opportunities, space and scope for the development of the talents of Indian youth and to develop more of those sectors which have been already been put under skill development. The new programme aims to identify new sectors for skill development and provide training for the same. This scheme has targets to provide skill training to 500 million youths in India by 2020 , covering each and every village.

The emphasis is on teaching skills to youths so that they are able to attain employment and also to improve entrepreneurship in India. The training programme would be provided at an international level so that the youths of our country can access jobs anywhere in world. It would create a hallmark called "Rural India Skill" so as to standardize and certify the training process. Tailor- made, need based programmes would be initiated for specific age group. i.e. communication, language, personality development, behavioral skills including job and employment skills etc.

Benefits:

- The idea is to raise confidence, improve productivity and give direction through proper skill development.

- It will reach to the rural and remote areas.

- Equal importance will be given to all the sectors and all jobs.

13. Pradhan Mantri Ujjwala Yojana: Launched: 1 May 2016

In India, the poor have limited access to cooking gas (LPG). The spread of LPG cylinders has been predominantly in the urban and semi-urban areas with the coverage mostly in middle class and rich households. However, there are serious health hazards associated with cooking based on fossil fuels. According to WHO 
estimates, there have been approximately 5 lakh deaths in India due to unclean cooking fuels. According to experts, having an open fire in the kitchen is like burning 400 cigarettes an hour.

The Cabinet Committee on Economic Affairs, chaired by the Prime Minister, has approved the Pradhan Mantri Ujjwala Yojana Scheme to provide free LPG connections to women from BPL households. Under the scheme, Rs 8000 crore has been earmarked for providing 5 crore LPG connections to BPL households. This is made possible by 1.13 crore users voluntarily giving up their subsidiaries.

This is the first time in the history of the country that the Ministry of Petroleum and Natural Gas would implement a welfare scheme benefitting crores of women belonging to the poorest households. This measure will empower women and protect their health. It will also provide employment for rural youth in the supply chain of cooking gas.

The scheme provides financial support of Rs 1600 for each LPG connection to a BPL households. This scheme would be implemented over 3 years, namely, the FY of 2016-17, 2017-18 and 2018-19.

\section{Conclusion}

Rural Development is not a one-time effort; it is an on-going process. It is a big dream of Prime Minister Modi, which requires concerted team efforts from all stake holders - the Government, financial institutions, the regulators, rural citizens and the community at large. The current government has already come up with so many social and financial alleviation schemes for the poor however, the fate of those unfortunates still remains a concern. Until the implementation and evaluation agencies work out the best ways to measure the success or failure of any scheme and come up with ways to reach the target population, things won't change at all. One day we will encounter a situation where the maximum rural poor will be benefited under the various government initiatives through ICT and technological developments. Recently, after demonetization in India, many initiatives have been successfully implemented in rural India and rural people are more aware of how to access government benefits. The presence of an extensive system would also lead to a boost in the economy and would also help to enable the rural population to take a part in the growth of India.

\section{References}

Bhatia, A. \& Kiran, C. (2016), Rural Development through E-Governance Initiatives in India, Journal of Business and Management, 61-69.

Gangopadhyay, D., Mukhopadhyay, A. K., \& Singh, P. (2008). Rural development: A strategy for poverty alleviation in India. India Science and Technology (Online).

Hussain, I., \&Hanjra, M. A. (2004). Irrigation and poverty alleviation: review of the empirical evidence. Irrigation and Drainage, 53(1), 1-15.

Jocelyn K. \& Amartya S. (1983) Indian Women: Well-Being and Survival, Journal of Economics, 7(3-4), 363-380.

Kanbur, R., \& Sumner, A. (2012). Poor countries or poor people? Development assistance and the new geography of global poverty. Journal of International Development, 24(6), 686-695.

Khuntia, R. (2014). Pradhan Mantri Jan DhanYojana (PMJDY): A new drive towards financial inclusion in India. Zenith International Journal of Business Economics \& Management Research, 4(11), 10-20.

NAIR, I. Challenges of Rural Development and Opportunities for Providing Sustainable Livelihood.111-118.

Petare, M. P. A. (2014). Information and communication technology for rural development, ASM International E-Journal of ongoing research management and IT, 1-8.

Rose, E. (1999). Consumption smoothing and excess female mortality in rural India. Review of Economics and statistics, 81(1), 41-49.

Santosh, M. (2013). The Government Monitoring and Evaluation System in India: A Work in Progress. World Bank Publications. 